\title{
Modified Transseptal Approach: An Adjunct to Prelacrimal Recess Approach for Extensive Inverted Papilloma of Maxillary Sinus, How We Do It
}

\author{
George Varghese, MS and Roshan Marie Thomas, MS \\ Department of ENT, GV ENT Clinic, Kerala, India
}

\begin{abstract}
The transseptal approach to the maxillary sinus has been described for resection of extensive tumours of the nose and paranasal sinuses. We describe a modification of this method in a patient diagnosed with inverted papilloma for which he had undergone two previous operations. This method provides complete access to the maxillary sinus, particularly the anterior wall, to provide adequate reach and ensure complete removal of tumours. We describe a technique modifying the existing transseptal approach used as an adjunct to prelacrimal recess approach, wherein a hemitransfixation incision placed in the contralateral nasal cavity along the septum provides access to the maxillary sinus with angled instruments. This modified transseptal approach provided better reach and access to the maxillary sinus. Postoperatively, there was no evidence of septal scarring or perforation and no evidence of lesion recurrence. Our technique is an easy modification to the transseptal approach that is a useful tool to access hidden areas of the maxillary sinus without associated morbidity.
\end{abstract}

Keywords: Nasal septum; Inverted papilloma; Maxillary sinus; Sinusitis.

\section{INTRODUCTION}

Of all the sinuses, the maxillary sinus stands the most diseased. This can be attributed to its pyramidal shape which makes access to its anterior and medial wall difficult, thereby leading to residual disease. Inverted papillomas, although relatively uncommon, are diagnosed in about $0.5 \%-4 \%$ of operated nasal tumours [1]. Among these, the most common site of origin of tumour remains the maxillary sinus [2]. Their high rate of recurrence is a harrowing problem for surgeons which makes its complete removal inevitable. Inverted papillomas have a tendency to invade surrounding bone which makes drilling out diseased bone necessary. Although several advanced techniques have been developed to clear maxillary sinus disease, the efficacy of these remain questionable. This can be attributed to the difficulty in access that most techniques accompany, leading to suboptimal clearance. The current gold standard for the treatment of maxillary sinus inverted papil-

Received: June 3, 2021 Revised: August 14, 2021

Accepted: August 27, 2021

Address for correspondence: George Varghese, MS, Department of ENT, GV ENT Clinic, Seaport- Airport Road, Kochi, Kerala 682037, India

Tel: +919447407706, E-mail: georgegogi@gmail.com

This is an Open Access article distributed under the terms of the Creative Commons Attribution Non-Commercial License (https://creativecommons.org/licenses/by$\mathrm{nc} / 4.0$ ) which permits unrestricted non-commercial use, distribution, and reproduction in any medium, provided the original work is properly cited. lomas remains to be endoscopic medial maxillectomy. Recent modifications to this technique such as the prelacrimal recess approach have provided improved access to the different recesses of the maxillary sinus [3]. When the sinus pathologies extend anteromedially, usage of angled instruments and endoscopes becomes imperative. However, these pose a problem of not providing adequate space and reach within a single nostril for manipulation and sharp dissection. Our technique describes a modification to transseptal approach described in the past [4] to access inverted papillomas with anteromedial origin and involvement of inner aspect of anterior wall of maxillary sinus.

\section{CASE REPORT}

A 54-year-old male presented with right sided nasal block and facial pain. He had similar complaints in the past and was diagnosed to have inverted papilloma for which endoscopic surgery was done twice, once in 2015 and later in 2019. Diagnostic nasal endoscopy was performed which revealed a polypoidal mass filling the nasal cavity on the right side (Fig. 1). Contrast enhanced magnetic resonance imaging of paranasal sinuses revealed an enhancing mass with a distinctive convoluted cerebriform appearance involving lateral wall of nasal cavity extending into maxillary ostium and antrum (Fig. 2). 
Surgical Technique: Surgery was performed under general anesthesia. Merocel ${ }^{\circledR}$ (Medtronic Xomed Inc., Jacksonville, FL, USA) soaked in adrenaline solution (1:1000) was used for local vasoconstriction. On the right side, minimal remnant of uncinate was removed. Following maxillary antrostomy, an incision was made anterior to the inferior turbinate and extended along the floor of the nose posteriorly (Fig. 3). The flap was then elevated exposing the entire lateral wall of the nose (Fig. 4). A $3 \mathrm{~mm}$ gouge was used to excise bone anterior to the nasolacrimal duct in a careful manner so as to avoid injury to the duct. The nasolacrimal duct was identified and transposed medially. This provided access to the anterior part of the maxillary sinus where the tumour remained hidden. Us-

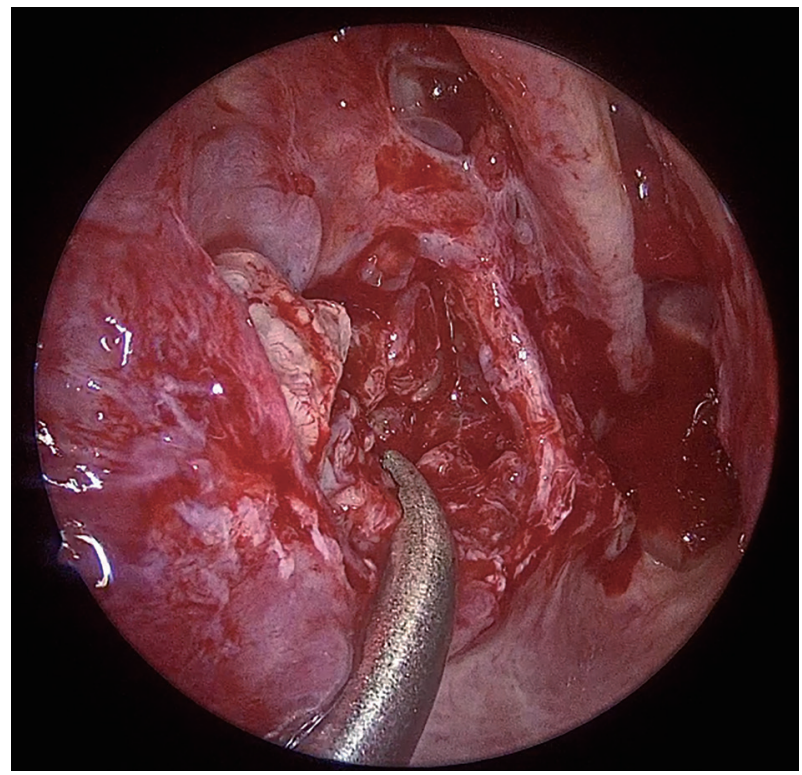

Fig. 1. Preoperative diagnostic nasal endoscopy.
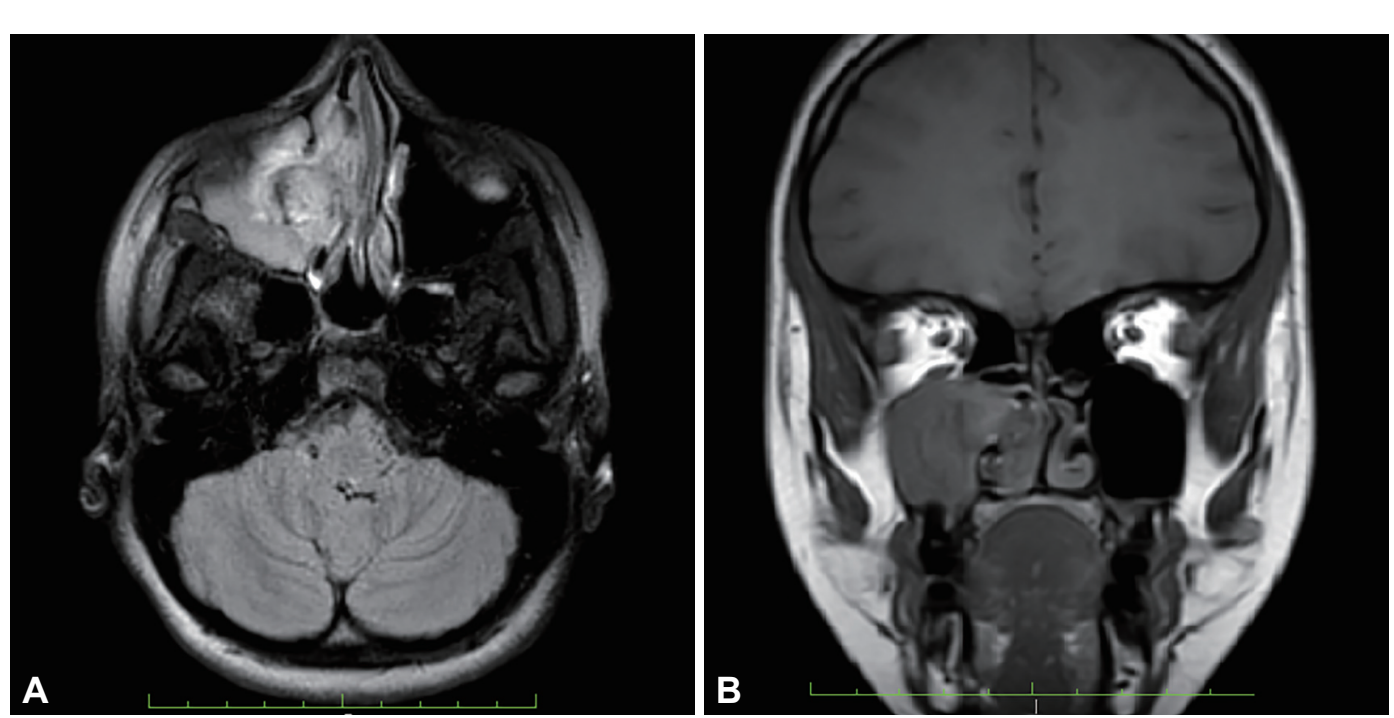

Fig. 2. Contrast enhanced magnetic resonance imaging of paranasal sinuses. (A) Axial and (B) coronal cut. ing burrs (Sinus Burr 35k, Karl Storz, Tuttlingen, Germany), the bone was drilled opening up the medial wall of the maxillary sinus. The visualised part of the tumour was removed using angled instruments (Heuweiser Forceps, Karl Storz, Tuttlingen, Germany). To gain access to the anteromedial wall and medial buttress, a hemitranfixation incision is made in the contralateral nasal cavity (left side) at the mucocutaneous junction. This incision was extended posteriorly, horizontal along the superior part of nasal septum beneath the nasal roof (Fig. 5). Mucoperichondrial and mucoperiosteal flaps were elevated on the contralateral side and folded posteroinferior-

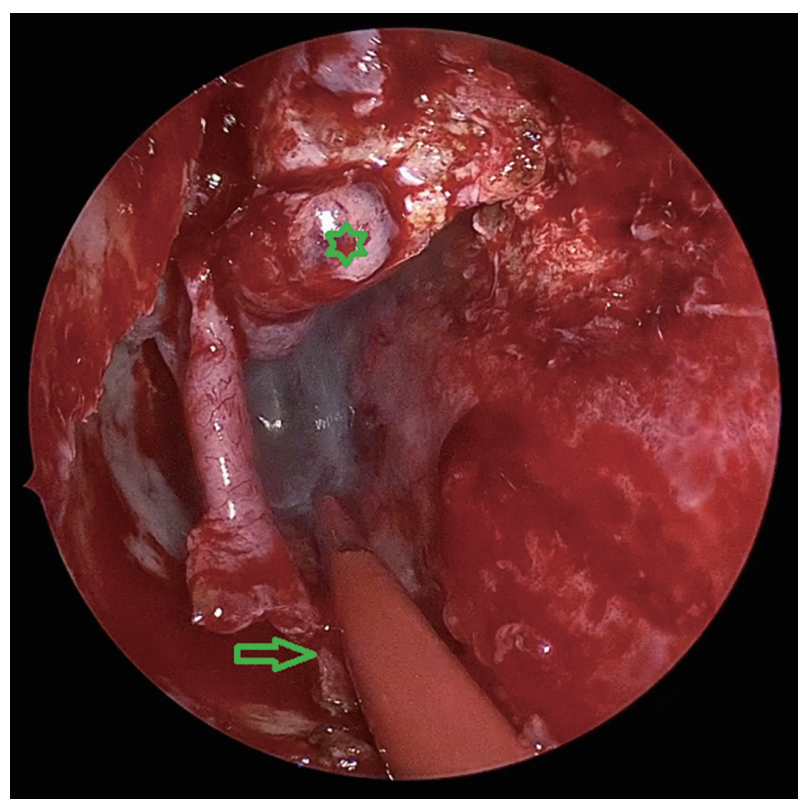

Fig. 3. Incision made anterior to right inferior turbinate and extended along the floor of nose, posteriorly (star indicates inverted papilloma and arrow indicates remnant of inferior turbinate). 


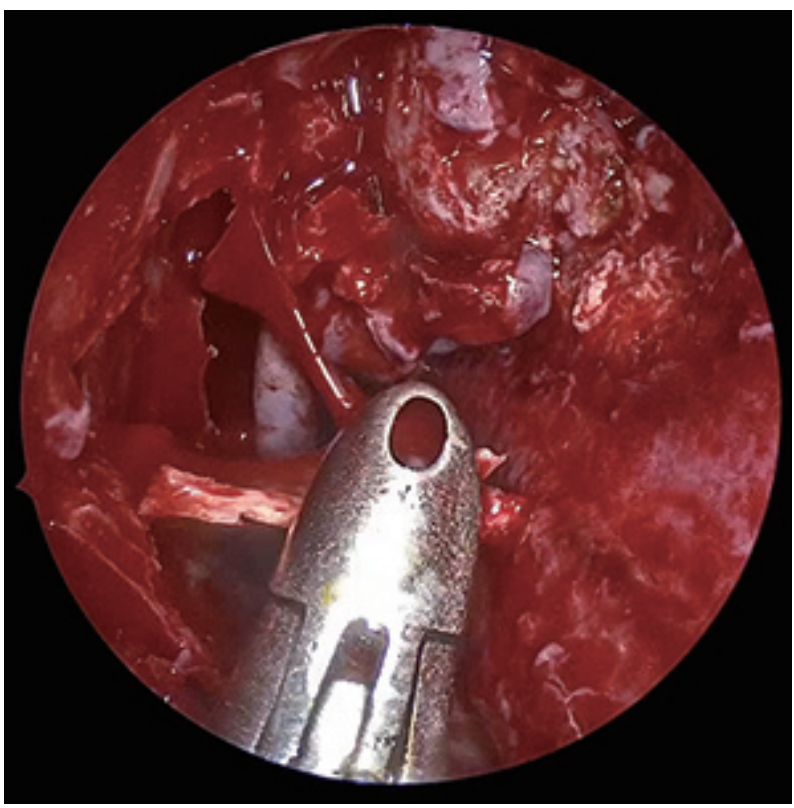

Fig. 4. Flap elevated exposing entire lateral wall of nose.

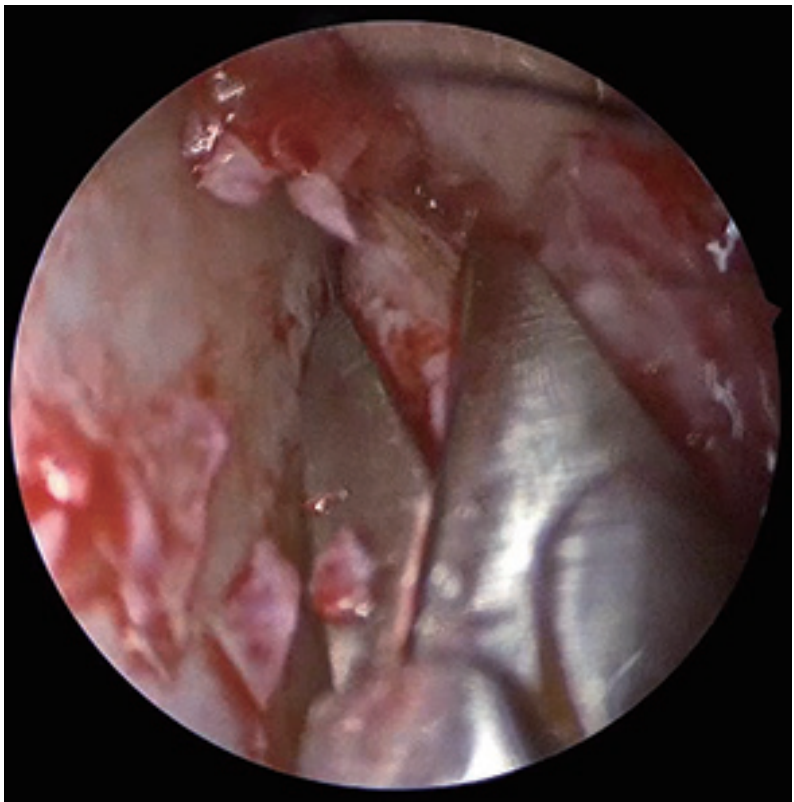

Fig. 5. Incision was extended posteriorly, horizontal along the superior part of nasal septum beneath the nasal roof (left side).

ly. The flap falls downwards, allowing space for instrumentation. From the ipsilateral side, a needle (Ethilon 3-0, Ethicon, Johnson and Johnson, Piscataway, NJ, USA) was passed through the septum, corresponding to the opening made on the medial wall of maxillary sinus (Fig. 6). Once the needle pierced beyond the septum on the contralateral side, a cruciate incision was made on the cartilage $(0.3 \mathrm{~cm} \times 0.3 \mathrm{~cm})$ (Fig. 7). Curved instruments (Rad Blades 15, 40 and 60 degree, Medtronic Xomed Inc., Jacksonville, FL, USA) of the powered debrider

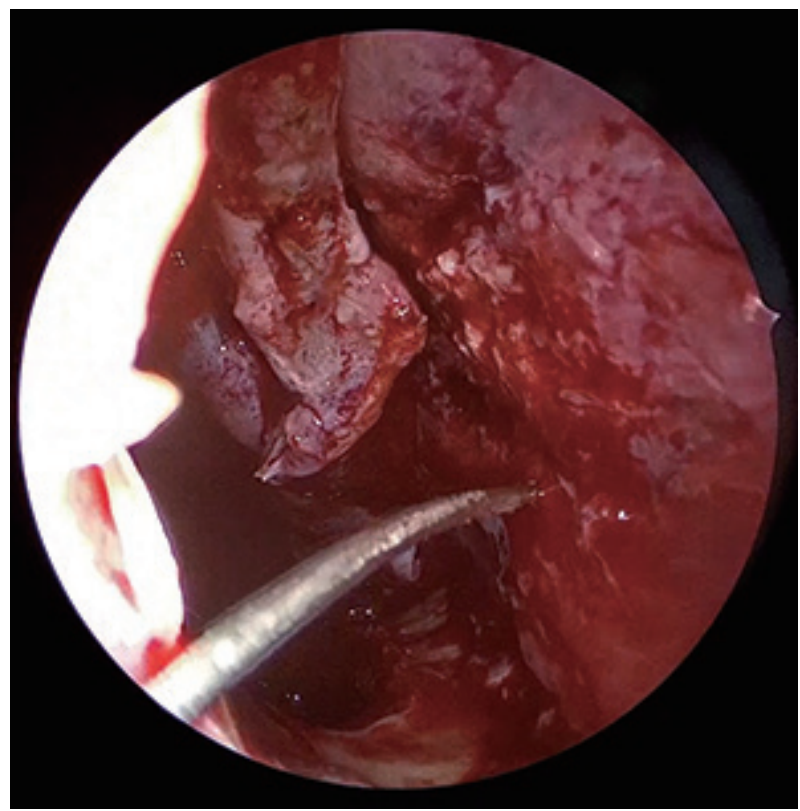

Fig. 6. A curved needle (Ethilon 3-0, Ethicon, Johnson and Johnson, Piscataway, NJ, USA) is introduced from the diseased side corresponding to the maxillary sinus opening.

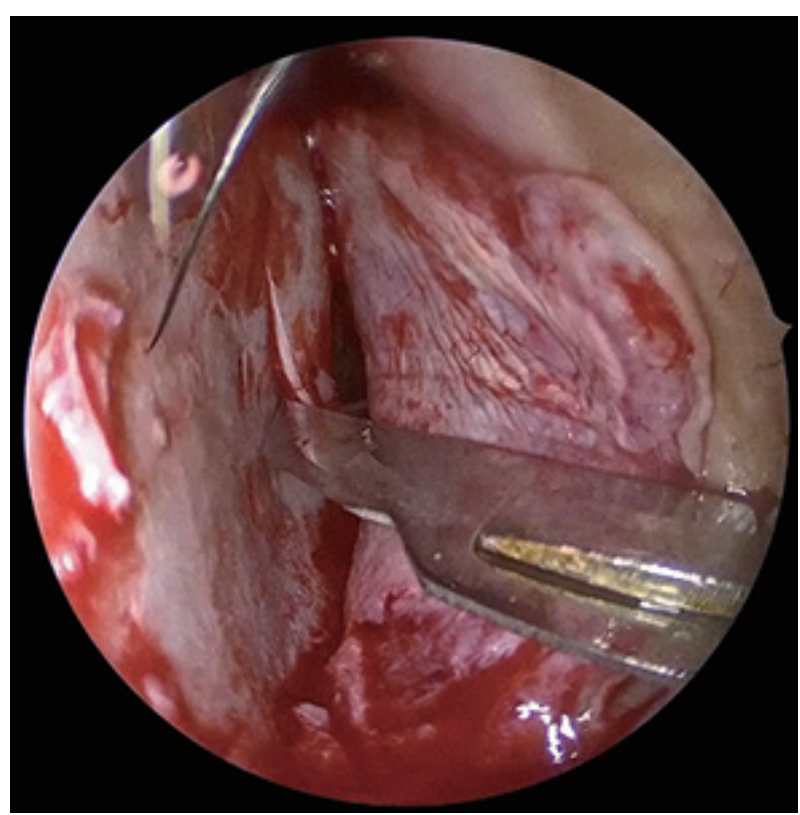

Fig. 7. Cruciate incision made along contralateral part of septal cartilage, corresponding to the point of entry of the curved needle (EthiIon 3-0, Ethicon, Johnson and Johnson, Piscataway, NJ, USA).

(Medtronic Xomed Inc., Jacksonville, FL, USA) were introduced through this incision providing access to the entire anterior wall of the maxillary sinus on the diseased side (Fig. 8). After tumour removal, the bone underneath its attachments was also drilled using a variety of angled burrs (The DrillCut- $\mathrm{X}^{\circledR}$ II-35 Handpiece with 35k Sinus Burrs, Karl Storz, Tuttlingen, Germany) in the range of $15^{\circ}, 40^{\circ}$ and $60^{\circ}$ (Fig. 9). 3-0 Vicryl 


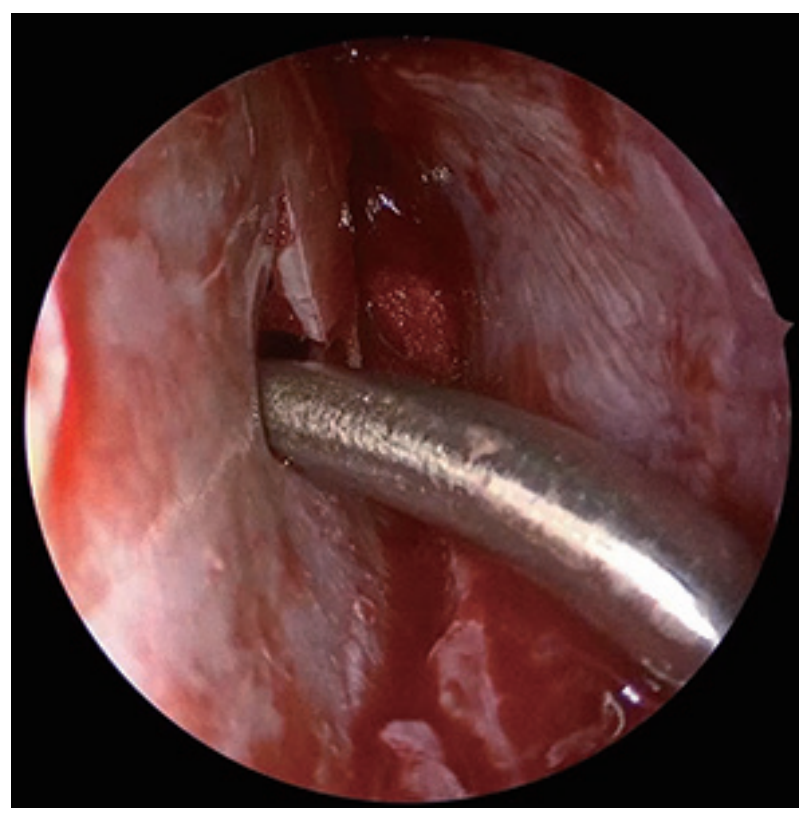

Fig. 8. Curved instruments (Rad Blades 15, 40 and 60 degree, Medtronic Xomed Inc., Jacksonville, FL, USA) are introduced through this incision providing access to entire anterior wall of maxillary sinus on diseased side.

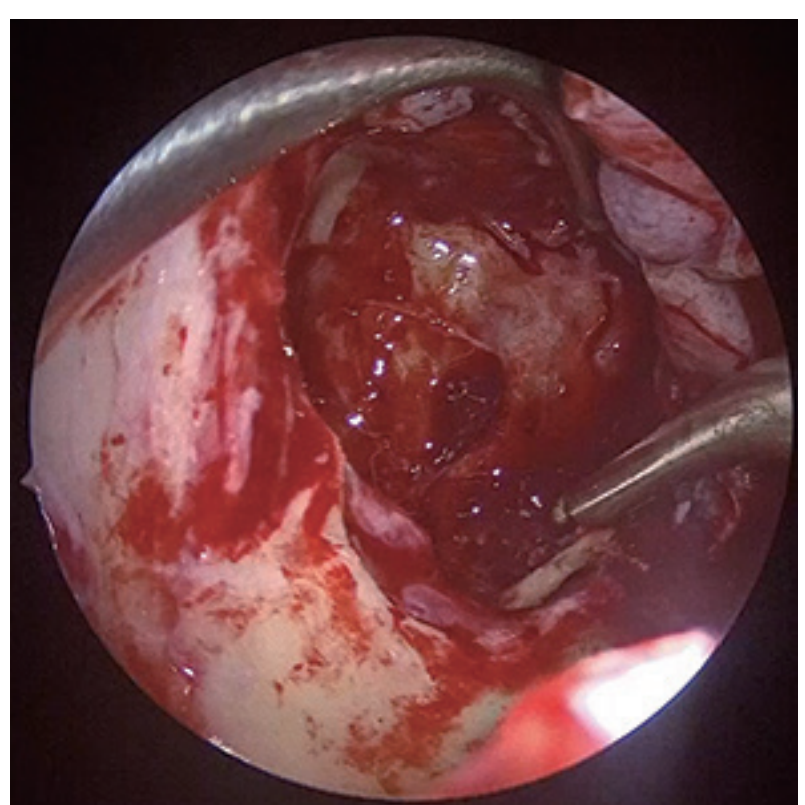

Fig. 9. Bone lying beneath tumour attachment is drilled.

Rapide $^{\mathrm{TM}}$ (Vicryl Rapide, Ethicon, Johnson and Johnson, Piscataway, NJ, USA) with a knot at one end [5] was used for septal suturing after replacing the mucoperichondrial and mucoperiosteal flaps (Figs. 10 and 11). The lateral wall flap was repositioned and the inferior turbinate was sutured anteriorly. Follow up period showed no crusting, perforation or epiphora. There were no signs of recurrence after a follow up period of one, three and six months. Due to drilling of bone, some de-

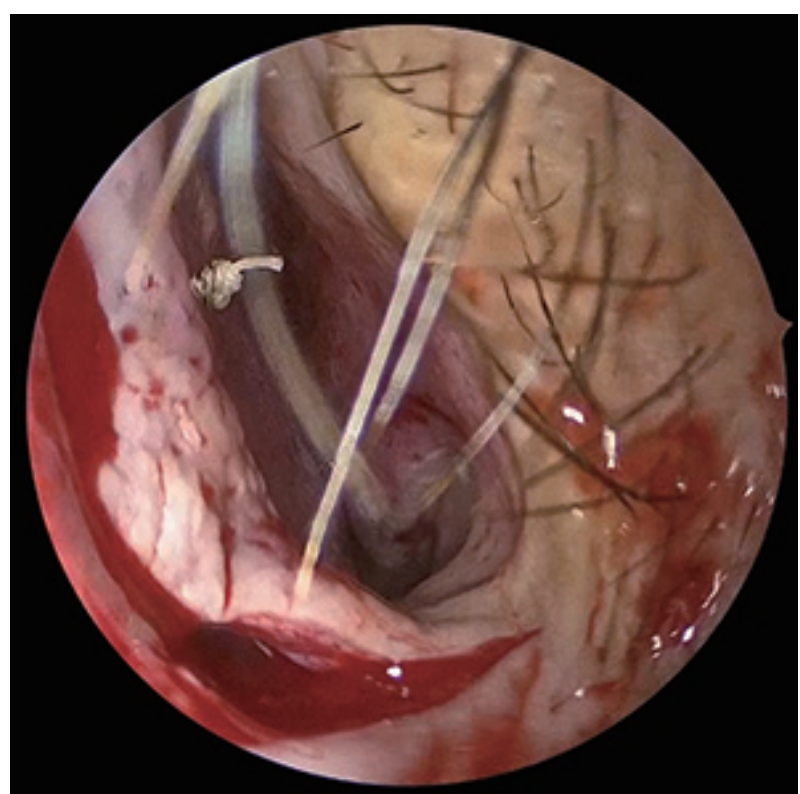

Fig. 10. The 3-0 Vicryl Rapide ${ }^{\mathrm{TM}}$ (Vicryl Rapide, Ethicon, Johnson and Johnson, Piscataway, NJ, USA) with a knot at one end was used for flap suturing.

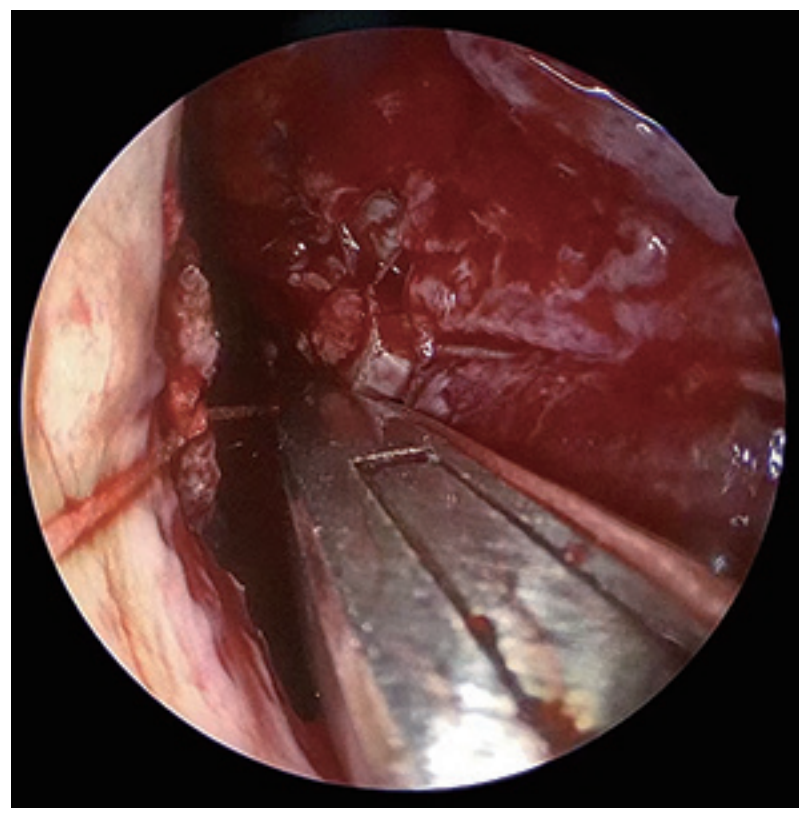

Fig. 11. Septal suturing done.

gree of maxillary contracture was observed.

\section{DISCUSSION}

In conditions such as inverted papilloma, it remains crucial to remove the tumour completely along with its underlying bone, as it houses microscopic cell rests that can lead to tumour progression [6]. However, it is the anatomy of the maxillary 
sinus that restricts optimum removal, increasing the recurrence rate due to residual disease. Hence based on the location and extent of tumour, an ideal surgical procedure should be chosen. Previously, Caldwell-Luc surgery and various open surgical procedures such as lateral rhinotomy and mid facial degloving were developed to provide access to the hidden buttresses of the maxillary sinus. These procedures are associated with some degree of morbidity and cosmetic deformities postoperatively. It also has limitations of providing restricted access and disruption of natural barriers of nose and paranasal sinuses. At present, the most common method to treat maxillary sinus inverted papillomas remains to be medial maxillectomy. Recent advances include intranasal endoscopic prelacrimal recess approach [7], however, the origin of tumour from the anteromedial wall of the maxillary sinus may remain hidden. Moreover, it remains difficult to use curved instruments in a single nostril to expose the sinus adequately. The concept of transseptal approach has been described in the past. The two-surgeon technique proposed by Douglas and Wormald [8] suggests to place a mucoperichondrial incision in the opposite nostril, remove part of bony septum and to make a mucoperichondrial incision on the side of lesion to allow access of angled instruments. This is the original technique wherein a second surgeon enters the nostril on the opposite side and through the septum introduces instruments to the ipsilateral side facilitating tumour dissection and manipulation. In this a hemi transfixation incision and superior incision are not made at the septum which will otherwise interfere with free manipulation using instruments, especially drills. Our technique modifies the original method by creating an additional incision at the superior aspect giving the advantage of having free, non-interfering access to the nasal septum. This has an additional advantage of helping to avoid accidental injury to the flap. Inverted papillomas in addition tend to invade the Haversian system of bone which warrants drilling of the bone underneath so as to avoid recurrence. In our case described, involvement of the anteromedial aspect of maxillary sinus (the medial buttress of maxillary sinus), access with a drill burr with any angulation would be impossible unless we come from the contralateral side. This is made possible by our modified transseptal approach. Cadaveric studies by Harvey et al. [4] have proved that transseptal approach improves angulation and dissection. Another cadaveric study by Ramakrishnan et al. [9] showed that a modified transseptal approach helped in providing access in the anterior and lateral direction. Dean et al. [10] also described transseptal approach to access tumours previously considered accessible with only external approaches. The need for transseptal surgery must be kept in mind while planning surgery. Once the origin of the tumour has been delineated, the tumour can be resected in a step wise manner.
The morbidity associated with this technique remains minimal. Our experience shows that this modification of transseptal technique is a useful tool in adjunct to endoscopic medial maxillectomy and prelacrimal approach to access hidden areas of the maxillary sinus. It appears to provide similar access as that of an open access approach without the associated morbidity such as alar retraction and facial numbness.

\section{Ethics Statement}

Informed consent was taken. The ethical approval was obtained as per institution regulations.

\section{Availability of Data and Material}

All data generated or analyzed during the study are included in this published article.

\section{Conflicts of Interest}

The authors have no potential conflicts of interest to disclose.

\section{Author Contributions}

Conceptualization: George Varghese. Resources: George Varghese. Supervision: George Varghese. Visualization: George Varghese. Writingoriginal draft: all authors. Writing—review \& editing: George Varghese.

\section{ORCID iDs}

George Varghese https://orcid.org/0000-0002-8801-0478

Roshan Marie Thomas https://orcid.org/0000-0002-5867-947X

Funding Statement

None

\section{REFERENCES}

1) Lund VJ, Stammberger H, Nicolai P, Castelnuovo P, Beal T, Beham A, et al. European position paper on endoscopic management of tumours of the nose, paranasal sinuses and skull base. Rhinol Suppl 2010;22:1-143.

2) Pagella F, Pusateri A, Matti E, Avato I, Zaccari D, Emanuelli E, et al. "TuNa-saving" endoscopic medial maxillectomy: a surgical technique for maxillary inverted papilloma. Eur Arch Otorhinolaryngol 2017; 274(7):2785-91.

3) Morrissey DK, Wormald PJ, Psaltis AJ. Prelacrimal approach to the maxillary sinus. Int Forum Allergy Rhinol 2016;6(2):214-8.

4) Harvey RJ, Sheehan PO, Debnath NI, Schlosser RJ. Transseptal approach for extended endoscopic resections of the maxilla and infratemporal fossa. Am J Rhinol Allergy 2009;23(4):426-32.

5) Hari C, Marnane C, Wormald PJ. Quilting sutures for nasal septum. J Laryngol Otol 2008;122(5):522-3.

6) Chiu AG, Jackman AH, Antunes MB, Feldman MD, Palmer JN. Radiographic and histologic analysis of the bone underlying inverted papillomas. Laryngoscope 2006;116(9):1617-20.

7) Yu QQ, Guan G, Zhang NK, Zhang XW, Jiang Y, Lian YY, et al. Intranasal endoscopic prelacrimal recess approach for maxillary sinus inverted papilloma. Eur Arch Otorhinolaryngol 2018;275(9):2297-302.

8) Douglas R, Wormald PJ. Endoscopic surgery for juvenile nasopharyngeal angiofibroma: where are the limits? Curr Opin Otolaryngol Head Neck Surg 2006;14(1):1-5.

9) Ramakrishnan VR, Suh JD, Chiu AG, Palmer JN. Septal dislocation for endoscopic access of the anterolateral maxillary sinus and infratemporal fossa. Am J Rhinol Allergy 2011;25(2):128-30.

10) Dean NR, Illing EA, Woodworth BA. Endoscopic resection of anterolateral maxillary sinus inverted papillomas. Laryngoscope 2015;125(4): $807-12$. 